\title{
As ilhas de fome e de exclusão social do "Brasil Sem Miséria": comentário sobre o artigo Insegurança alimentar em povos de terreiros
}

\author{
Francisco de Assis Guedes de Vasconcelos
}

Departamento de Nutrição do Centro de Ciências da Saúde da Universidade Federal de Santa Catarina (UFSC) - Trindade (SC), Brasil. E-mail: f.vasconcelos@ ufsc.br

DOI: http://dx.doi.org/10.7322/abcshs.v39i1.245

A sociedade brasileira desfrutou relevantes mudanças econômicas, políticas, sociais, culturais, sanitárias e nutricionais nas três últimas décadas. No campo nutricional, em estudo anterior ${ }^{1}$ apontamos que foram verificadas importantes mudanças paradigmáticas. Observamos que ao perfil epidemiológico nutricional que caracterizou a sociedade brasileira no período 1930-1980, constituído sobretudo pelas doenças carenciais (desnutrição energético-proteica, deficiência de vitamina A, pelagra, anemia ferropriva, deficiência de iodo etc.), no período de 1990 aos dias atuais sobrepuseram-se as doenças nutricionais crônicas não transmissíveis (obesidade, diabetes, dislipidemias, hipertensão, certos tipos de câncer etc.), caracterizando o chamado fenômeno de transição nutricional no país.

A redefinição e ampliação de políticas públicas nos campos da alimentação e nutrição, assistência social, educação, saúde, trabalho e emprego tem contribuído com a redução das desigualdades sociais e permitido que o país cresça de forma mais inclusiva nas últimas décadas. No campo da política social de alimentação e nutrição, ao longo das últimas décadas, sobretudo a partir da instituição do Programa Fome Zero em 2003, importantes avanços têm sido identificados, tanto em termos de alocação de recursos financeiros, como de cobertura populacional, como do estabelecimento de critérios técnicos, conceituais e operacionais visando maior flexibilidade, eficiência e eficácia na gestão dos programas².

Em termos de alocação de recursos financeiros e cobertura populacional, destacamos a atuação do Programa Bolsa Família e do Programa Nacional de Alimentação Escolar (PNAE). O Programa Bolsa Família, instituído pelo governo federal em 2004, integra o atual Plano Brasil Sem Miséria, do governo Dilma Rousseff, tendo como foco de atuação 16 milhões de brasileiros com renda familiar per capita inferior a R 70 mensais e por objetivos a garantia de renda, a inclusão produtiva e o acesso aos serviços públicos dos seus beneficiários 3 . O PNAE, por sua vez, constitui a política pública de segurança alimentar e nutricional de maior longevidade do país, perfazendo quase 60 anos de existência, sendo considerado um dos maiores e mais abrangentes programas de alimentação escolar do mundo, cujo orçamento para 2014 é de R \$3,5 bilhões para beneficiar 43 milhões de estudantes da educação básica, jovens e adultos ${ }^{4}$. No campo do estabelecimento de critérios técnicos, conceituais e operacionais visando maior flexibilidade, eficiência e eficácia na gestão dos programas de alimentação e nutrição, múltiplos são os exemplos que merecem ser destacados. Um primeiro exemplo diz respeito à atuação do Conselho Nacional de Segurança Alimentar e Nutricional (CONSEA). Recriado em janeiro de 2003, o CONSEA constitui uma instância de articulação entre governo e sociedade civil, de caráter consultivo e com objetivo de assessorar a Presidência da República na formulação de políticas e na definição de orientações para que o país garanta o direito humano à alimentação adequada e saudável em todas as suas dimensões e, inclusive, em suas relações exteriores ${ }^{5}$. O segundo exemplo que destacamos foi a aprovação da Lei Orgânica de Segurança Alimentar e Nutricional (LOSAN), lei federal nº 11.346, de 15 de setembro de 2006 , que estabelece as definições, princípios, diretrizes, objetivos e composição do Sistema Nacional de Segurança Alimentar e Nutricional (SISAN), por meio do qual o poder público, com a participação da sociedade civil organizada, formula e implementa políticas, planos, programas e ações com vistas em assegurar o direito humano à alimentação adequada ${ }^{6}$. O terceiro exemplo corresponde à promulgação pelo Congresso Nacional, em 04 de fevereiro de 2010, da emenda no 64 à Constituição Federal de 1988, que incluiu em seu artigo $6^{\circ}$ a alimentação como um dos direitos sociais de todo brasileiro ${ }^{7}$. O quarto exemplo diz respeito à divulgação, em agosto de 2011 pela Câmara Interministerial de Segurança Alimentar e Nutricional (CAISAN), do Plano Nacional de Segurança Alimentar e Nutricional 2012/2015 ${ }^{8}$. O quinto exemplo que destacamos é a publicação da portaria no 2.715 do Ministério da Saúde, de 17 de novembro de 2011, que atualiza a Política Nacional de Alimentação e Nutrição (PNAN) ${ }^{9}$. Por último, destacamos a publicação conjunta pelos Ministérios do Desenvolvimento Social e Combate à Fome (MDS), da Saúde (MS) e da Educação (ME), em novembro de 2012, do Marco de Referência de Educação Alimentar e Nutricional (EAN) para Políticas Públicas ${ }^{10}$.

Entretanto, em decorrência da complexa multiplicidade dos processos históricos de produção e reprodução da fome e da miséria no Brasil para segmentos específicos da sociedade brasileira como comunidades indígenas, quilombolas, sem terra, sem teto e povos de terreiros, os benefícios das políticas públicas de inclusão social ainda não foram suficientes para eliminar a enorme dívida social do país com tais populações ${ }^{1,2,11-14}$. 
Nesse sentido, ressaltamos a pertinência e oportunidade da publicação do artigo Insegurança alimentar em povos de terreiros ${ }^{11}$ pelos Arquivos Brasileiros de Ciências da Saúde, o qual, no cenário nacional, onde ainda são muito escassas as publicações científicas sobre as condições e os modos de vida dos povos de terreiros e de outros povos tradicionais, nos traz importantes revelações. Os resultados encontrados revelam que 79,6\% dos povos de terreiros de Teresina, Piauí, convivem em situação de insegurança alimentar, valores superiores à média estadual (58,6\%) e duas vezes maiores do que a média nacional (30,2\%), quando comparados com aqueles verificados pela Pesquisa Nacional por Amostra de Domicílios (PNAD) realizada pelo Instituto Brasileiro de Geografia e Estatística (IBGE) em 2009 ${ }^{11}$. Tais achados fazem emergir as ilhas de fome, de miséria e de exclusão social que permanecem encobertas, mas que ainda se espalham pelo território nacional. Conforme concluem os autores do artigo, os resultados encontrados "indicam a violação do direito humano à alimentação adequada vivenciada por esse grupo e reforçam a necessidade do poder público agir mais efetivamente com ações de proteção social junto a esses povos"11.

Como limitação do instrumento usado para medir a (in)segurança alimentar, a Escala Brasileira de Insegurança Alimentar (EBIA), é preciso ressaltar que o mesmo não é capaz de revelar a riqueza histórica, social e antropológica contida nos hábitos e ideologias alimentares dos povos de terreiros ${ }^{12-14}$. Ressaltamos que exigir essa capacidade/habilidade da EBIA é, no mínimo, uma crítica inconsequente, uma vez que esse instrumento não foi desenhado com esse propósito ${ }^{11}$. No entanto, fica a recomendação para a realização de estudos qualitativos, etnográficos, históricos e sociológicos que possibilitem compreender a complexidade simbólica e nutricional dos ritos alimentares dos povos de terreiros ${ }^{12-14}$.

Os povos de terreiros, conforme os autores do artigo dão pistas, mas não as percorrem, têm um modo de vida bem singular. Para eles, além da dimensão material/nutricional, o ato alimentar conserva, sobretudo, uma dimensão simbólica/espiritual ${ }^{11}$. Sendo assim, cada item da pauta de consumo alimentar — alimento, comida, bebida - , bem como outros itens de consumo como roupas, adereços e perfumes possui, de forma isolada ou combinada com outros, um caráter simbólico, estando associado à determinada divindade, santo ou orixá. Deriva daí os alimentos preferenciais ou obrigatórios do cardápio de determinados santos ou orixás, bem como o sistema de interditos, tabus ou quizilas gerados pelos desgostos, repulsa e aversão que certos santos ou orixás têm por outros alimentos ${ }^{11-14}$. Além disso, os padrões de alimentação dos povos de terreiros parecem estar assentados em sistemas alimentares que protegem e respeitam o ambiente natural de onde os alimentos são obtidos ${ }^{11-13}$, estando, portanto, em sintonia com as teorias da sustentabilidade ecológica do planeta ${ }^{1}$.

$\mathrm{Na}$ oportunidade, reafirmamos a relevância, a originalidade e atualidade da temática abordada nesse artigo, o qual constitui contribuição pioneira não apenas para os cientistas do campo das Ciências da Saúde, mas para todos aqueles que lutam pela garantia do direito humano à alimentação adequada, saudável e sustentável para todos os brasileiros.

\section{REFERÊNCIAS}

1. Vasconcelos FAG. A ciência da nutrição em trânsito: da nutrição e dietética à nutrigenômica. Rev Nutr. 2010;23(6):935-45.

2. Vasconcelos FAG. Combate à fome no Brasil: uma análise histórica de Vargas a Lula. Rev Nutr. 2005;18(4):439-57.

3. Brasil. Ministério do Desenvolvimento Social e Combate à Fome (MDS) [Internet]. Bolsa Família. Disponível em: http://www.mds.gov.br/ bolsafamilia. Acesso em: 31 mar. 2014

4. Brasil. Fundo Nacional de Desenvolvimento da Educação (FNDE) [Internet]. Programa Nacional de Alimentação Escolar (PNAE). Apresentação. Disponível em: http://www.fnde.gov.br/programas/ alimentacao-escolar/alimentacao-escolar-apresentacao. Acesso em: 31 mar. 2014.

5. Brasil. Ministério do Desenvolvimento Social e Combate à Fome (MDS) [Internet]. Conselho Nacional de Segurança Alimentar e Nutricional (CONSEA). Disponível em: http://www.mds. gov.br/falemds/perguntas-frequentes/seguranca-alimentare-nutricional/sesan-institucional/sesan-institucional/conseaconselho-nacional-de-seguranca-alimentar-e-nutricional. Acesso em: 31 mar. 2014.

6. Brasil. Presidência da República. Casa Civil [Internet]. Lei federal n 11.346, de 15 de setembro de 2006. Disponível em: http://www. planalto.gov.br/ccivil_03/_ato2004-2006/2006/lei/l11346.htm. Acesso em: 31 mar. 2014

7. Brasil. Presidência da República. Casa Civil [Internet]. Emenda constitucional $n^{\circ}$ 64, de 04 de fevereiro de 2010. Disponível em:
http://www.planalto.gov.br/ccivil_03/constituicao/Emendas/Emc/ emc64.htm. Acesso em: 31 mar. 2014.

8. Brasil. Câmara Interministerial de Segurança Alimentar e Nutricional (CAISAN) [Internet]. Plano Nacional de Segurança Alimentar e Nutricional: 2012/2015. Disponivel em: http://www.mds.gov.br/ segurancaalimentar/arquivos/LIVRO_PLANO_NACIONAL_CAISAN_ FINAL.pdf. Acesso em: 31 mar. 2014.

9. Brasil. Ministério da Saúde [Internet]. Política Nacional de Alimentação e Nutrição. Disponível em: http://189.28.128.100/nutricao/docs/geral/ pnan2011.pdf. Acesso em: 31 mar. 2014.

10. Brasil. Ministério do Desenvolvimento Social e Combate à Fome (MDS) [Internet]. Marco de Referência de Educação Alimentar e Nutricional para as Políticas Públicas. Disponível em: http://www.ideiasnamesa. unb.br/files/marco_EAN_visualizacao.pdf. Acesso em: 31 mar. 2014.

11. Carvalho RRS, Alberto NSMC, Pereira TG. Insegurança alimentar em povos de terreiros. ABCS Health Sci. 2014;39(1):4-11. http://dx.doi.org/10.7322/abcshs.v39i1.252.

12. Mota CS, Trad LAB. A gente vive pra cuidar da população: estratégias de cuidado e sentidos para a saúde, doença e cura em terreiros de candomblé. Saude soc. 2011;20(2):325-37.

13. Bassi F. Revisitando os tabus: as cautelas rituais do povo de santo. Relig Soc. 2012;32(2):170-92.

14. Santos JT, Santos LCC. "Pai de santo doutor": escolaridade, gênero e cor nos terreiros baianos. Afro-Ásia. 2013;(48):213-36. 